\title{
Method of rapid assessment of sulfide sulfur content in host rocks
}

\author{
Rostislav Magomet ${ }^{1, *}$, Sergey Zhikharev ${ }^{2}$, Stanislav Maltsev², and Nadezhda Norina $^{2}$ \\ ${ }^{1}$ Saint-Petersburg Mining University, 2, 21 Line V.O., 199002, St. Petersburg, Russia \\ ${ }^{2}$ Mining Institute of the Ural Branch of the Russian Academy of Science, 78a, \\ Sibirskaya st. 614007, Perm, Russia
}

\begin{abstract}
The aim of the research is to assess the possibility of using the energy-dispersive $\mathrm{X}$-ray fluorescence method directly at the stoping operation site. To meet this objective, a hand-held X-ray fluorescence spectrometer of the expert class of the NITON XL2 brand was selected. This will solve the problem of developing an express method for assessing the explosive and fire-hazardous properties of sulfur-containing or pyritecontaining ore. The development of the method is dictated by the need for operational control of the dust explosion hazard of sulfur-containing rocks and the assessment of their tendency to spontaneous combustion and also the possibility of making amendments to the development process of complex heterogeneous host rocks. Visual and optical control methods were used as an auxiliary method. In the process of developing the express method, both express analyses were carried out directly at the face bottom, and monolithic large-sized pieces of mined rock mass and also additional laboratory studies of previously studied samples of these rocks dispersed to a size of less than 100 microns were performed. The obtained results allowed to draw a number of conclusions about the expediency of using the $\mathrm{X}$-ray fluorescence express method and suggest ways to use it directly in the stoping face.
\end{abstract}

\section{Introduction}

Changing geological, mining and climatic conditions for the mined and prospective fields development, the complexity of the geomechanical situation, the increase in production, the use of innovative technologies for tunneling and drilling and blasting operations, the increasing need for mining polymetallic raw materials dictate the need to improve the existing rules and regulations governing industrial safety issues [1, 2, 3]. First of all, the specification of sections on ensuring industrial mine safety of sulfur-containing polymetallic ores. In addition, this need is dictated by an increase in the total amount of fine dust component, and also the involvement in more deeply located complex sulfide ores development $[1,2,4]$. The implementation of high-tech mining equipment requires timely regulatory and law measures aimed at reducing (completely preventing) the risk of initiating spontaneous heating foci and their further transition to ezogenous combustion

${ }^{*}$ Corresponding author: 79213258397@mail.ru 
foci, and also reducing the probability of an explosion. The need to find new solutions to improve industrial safety, namely, the development of methods for preventing spontaneous combustion and explosion processes, innovative methods for integrated monitoring of the mine workings space and, above all, the face (stoping sites) is confirmed not only by Russian scientists in their works, but also by their foreign colleagues [2, 5-11]. For example, the hazardous content of bound sulfur in rocks at which processes of spontaneous combustion are not excluded and dust explosion is possible starts from $18 \%$, such a regulatory requirement is contained in the Guidelines of the Department of Industry and Resources of Australia, while in a number of other countries, including Russia, the sulfur content is $35 \%$ [2, $6,12-14]$. Due to the fact that a number of works provide information on multiple spontaneous combustion and dust explosions in mine workings, and also the above discrepancies on the dangerous threshold of sulfur content in the rocks containing the ore body, we consider it necessary to have regulatory requirements or recommendations for the use as a preventive measure of assessing the danger of polymetallic rocks mining including sulfur and sulfur-containing minerals for the widespread implementation of express methods for assessing the sulfur content in the rock mass [15-19]. One of these express methods is the energy-dispersive X-ray fluorescence analysis method. Modern applied material and technical support makes it possible to implement the application of this method directly at the underground ore mining site [14, 20].

\section{Materials and methods}

\subsection{Materials}

Samples for the study were taken from three working horizons (1480, 1500 and 1516) of one of the polymetallic ore deposits in Russia. The ore bodies of the deposit have the form of a linear stockwork oriented subconcordantly with the dike in the latitudinal direction. According to the mining and geological characteristics of the ore bodies of the deposit, they are composed mainly of tin-cassiterite ores, which have a relatively simple mineral and chemical composition. The deposit has five assemblages: quartz-sericite (quartzmuscovite), quartz-biotite, cassiterite-quartz-topaz, quartz-tourmaline and quartz-sericitecarbonate. The ore body has an inhomogeneous layered structure, in which sulfurcontaining and arsenic-containing rocks are found in a wide range, as shown in Table 1.

Table 1. Sulfur and arsenic content in typical sulfide and sulfide-arsenic minerals.

\begin{tabular}{|l|c|c|c|}
\hline Mineral & Chemical formula & Sulfur, \% & Arsenic, \% \\
\hline Pyrite & $\mathrm{FeS}_{2}$ & 53.3 & - \\
\hline Chalcopyrite & $\mathrm{CuFeS}_{2}$ & 34.9 & - \\
\hline Sphalerite & $\mathrm{ZnS}$ & 32.9 & - \\
\hline Galena & $\mathrm{PbS}$ & 13.4 & - \\
\hline Arsenopyrite & $\mathrm{FeAsS}$ & 19.6 & 46.0 \\
\hline Loellingite & $\mathrm{FeAs} 2$ & - & 72.82 \\
\hline
\end{tabular}

The most common sulfur-containing minerals in descending order are chalcopyrite, sphalerite, arsenopyrite and pyrite. Pyrite inclusions have the form of separate small grains. Arsenic, in large enough quantities, in addition to arsenopyrite, presented in the form of loellingite. The content of sulfur and arsenic in these minerals in the host rocks ranges from 0.01 to $25 \%$. In addition, a number of mine workings due to the high content of silicon are classified as silica-hazardous.

Thus, when determining the possibility of using the X-ray fluorescence analysis (XRF) method as an express method for assessing the content of hazardous components in the ore body, 12 groups of samples were selected from each of the horizons directly from the 
stoping face. The total weight of each group was from 15 to $20 \mathrm{~kg}$. In each group there were large pieces of rock, at least $5 \mathrm{~kg}$ of one sample from the group, freshly mined rock mass. After the XRF, a bore core was cut out of the largest pieces, from which several cuts were made. After an external visual and optical inspection of the bore core and cuts, the samples were sorted. Optical inspection of the bore core and cuts from it was carried out by analyzing photographs of samples obtained using a Sony $\alpha 5000$ camera equipped with a standard macro lens [2, 14, 18]. As a result, three most characteristic groups were identified. As an example, Figure 1 shows the bore core of one of the ore body samples under study and Figure 2 shows the bore core cuts.

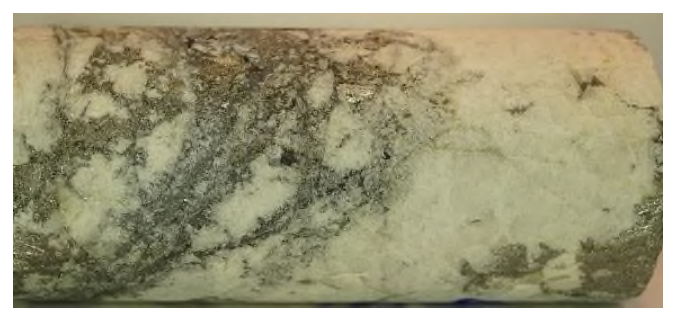

Fig. 1. The bore core of one of the ore body samples under study, from which the cut shown in Figure 2 is obtained at number 4 .

The geometrical characteristics of the sample: the bore core sample height is $0.1 \mathrm{~m}$ and a diameter $-4 \cdot 10^{-2} \mathrm{~m}$; the bore core cut diameter $-4 \cdot 10^{-2} \mathrm{~m}$, and the thickness (sample height) $5 \cdot 10^{-2} \mathrm{M}$.

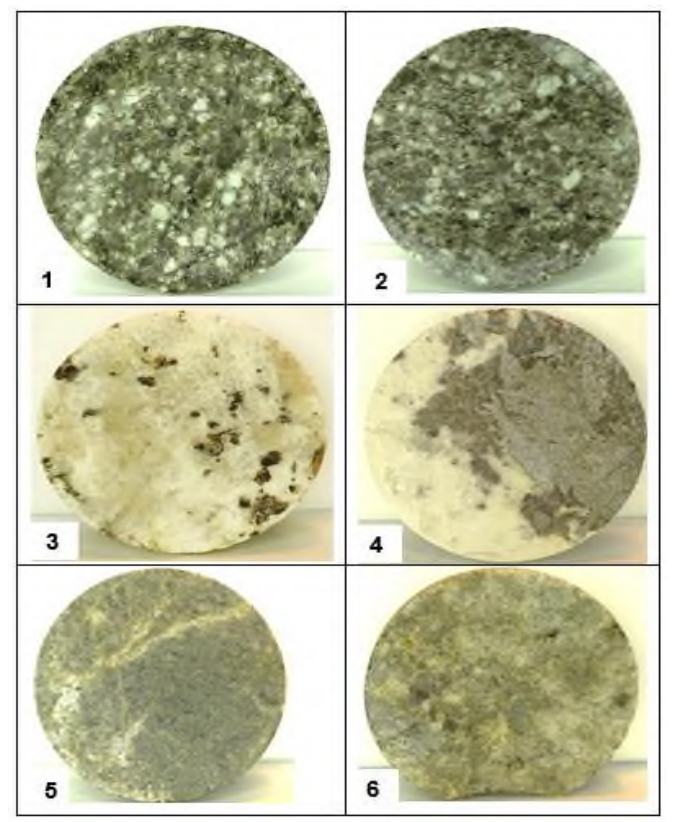

Fig. 2. Bore core cuts of the ore body: 1 and 2 tuff liparite; 3, 4, 5 and 6 quartz metasomatites, with arsenopyrite, tourmaline.

The obtained bore core samples and, above all, cuts, confirmed the heterogeneity of the ore body. This allowed to conclude that as samples for XRF analysis, it is necessary to take rock dust formed during drilling of the hole or rock mass during its further deepening. In the event that such a possibility is not available for one reason or another, then it is necessary to study more samples of the mined rock mass from all sides. Further XRF studies were carried out with samples dispersed to a fraction of 0-100 microns. 


\subsection{Methods}

Additional methods were the methods of visual inspection and the analysis method of photographs taken with the Sony $\alpha 5000$ equipped with a standard macro lens. They allowed the samples to be sorted into working groups, but belonging to the same sampling site. The main method that we propose to use as an express method for determining elements, in this case, sulfur and arsenic, is the method of X-ray fluorescence analysis.

The selection of this method and instrumentation is not accidental. First of all, the XRF method is unique in its capabilities, belongs to the group of express methods (the result can be obtained from 5 seconds), is highly accurate, informative, and also has good reproducibility of results. It can be implemented both with the help of stationary and portable (hand-held) devices. This method allows qualitative, semi-quantitative and quantitative determination of all elements from beryllium to uranium in powdered, solid and liquid samples [2, 14]. Currently, the devices that allow you to perform XRF and application software to them are highly scientific, intuitive for their use by an untrained operator equipment. In addition, the devices for conducting XRF in a portable version are made in their design specifically for use in the underground mine space. Of course, handheld devices cannot replace an entire laboratory, but they can and do allow rapid analysis of the elemental rocks content. Due to the rapid generation of dynamic data in real time and directly without going to the surface, the XRF method will allow to quickly respond to changes in the elemental ore composition. This will most likely permit making certain adjustments related both to the mining of minerals, and will increase industrial safety by timely responding to an increase in the content of explosive combustible components of the ore body. To solve this problem, we used the hand-held devices at our disposal, presented in Figure 3, which let us conduct XRF analysis of rocks.
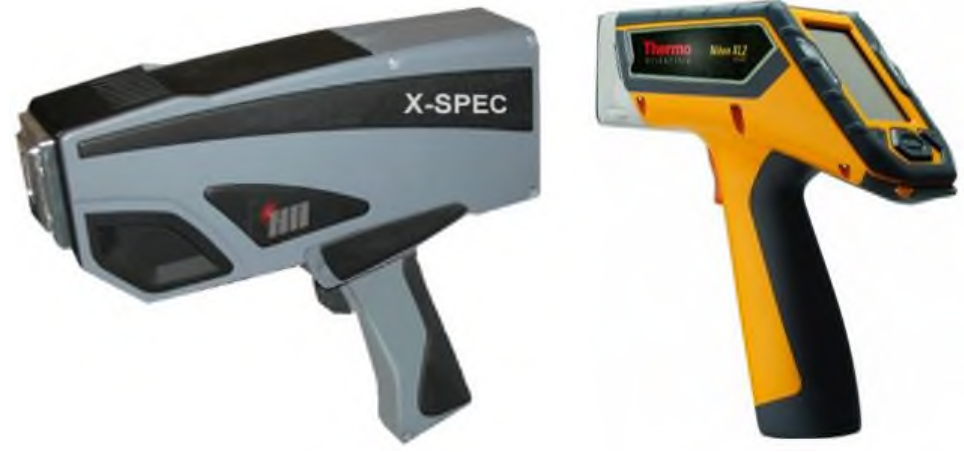

Fig. 3. Portable X-ray fluorescence spectrometers: left - X-SPEC-50H; right-Thermo Scientific NITON XL2.

Currently, it is impossible to say definitely which of the devices designed to perform $\mathrm{XRF}$ is better, since this will depend primarily on the purpose of its use. In our case, both devices performed well, but it was more convenient to work with the NITON XL2. The main results were obtained on it. It is designed for non-destructive measurement of the mass fraction of chemical elements in substances and materials in a solid, powdery or liquid state. The Thermo Scientific NITON XL2 has a built-in computer that runs the industrial operating system Nucleus RTOS. In addition, it has a specialized base for studying the composition of mining materials. Depending on the set tasks, both devices can detect elements when operating in the study mode from 5 seconds. To work on the X-SPEC-50H, sample preparation was carried out. It consisted in grinding a monolithic sample to a particle size of less than 50 microns. Then, a tablet was made from the resulting powdered sample by pressing, which was studied. When running the NITON XL2, we worked with 
solid pieces of rock and a dispersed combined sample. Samples with a particle size of less than 100 microns were studied.

\section{Discussion and results}

Taking into account the fact that two X-SPEC-50H and NITON XL2 XRF devices were used in this work, the obtained result is presented both in the form of spectrograms and bar charts, and in the form of tables. Depending on the specific goal, each researcher decides for himself how to visualize the result of his work in order to obtain more information about the test substance. In our case, we believe that the most appropriate task for us is to visualize the result in the form of bar charts. Directly in the mine working, the finished measurement result can be visualized on the device monitor as a percentage of elements. Figure 4 shows a spectrogram of one of the studied samples obtained using X-SPEC-50H, which displays only elements belonging to metals [14].

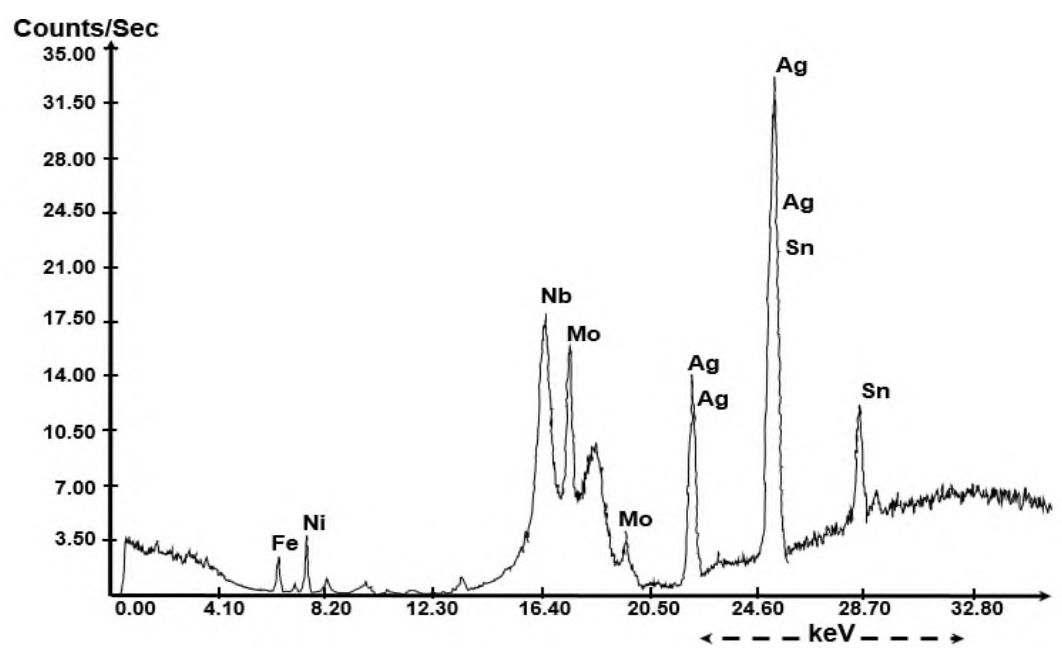

Fig. 4. X-SPEC-50H ore sample spectrogram.

As already noted, samples from three horizons (1480, 1500 and 1516) were analyzed. After studying them, they were formed taking into account the place of selection in three groups. The first group included samples of liparite tuff taken from the stoping faces of each horizons. The second and third groups included samples containing the main ore body, namely quartz metasomatites with arsenopyrite and tourmaline. Due to the fact that the samples were tested under laboratory conditions, it was necessary to follow the recommendations set out in the passport of each devices. However, different detection times were tried during the studies. As a result, it was experimentally established that for these samples, the required detection time should be at least $30 \mathrm{~s}$. When the minimum allowable time for determining the content of elements in samples is $5 \mathrm{~s}$, not all elements are detected and the result is doubtful. Therefore, it was decided to follow the recommendations of the user's guide for conducting XRF on the NITON XL2, in which the detection time when working with rocks was recommended to be $120 \mathrm{~s}$. The results of the determination of elements in liparite tuff samples are shown in Figure 5 and Table 2.

For a better visualization of the obtained results, concentration values expressed in $\%$ were used when plotting graphs for the concentration scale (Y). On the X-scale, the scale of elements, only the elements determined as a result of the XRF analysis of the sample are located. 


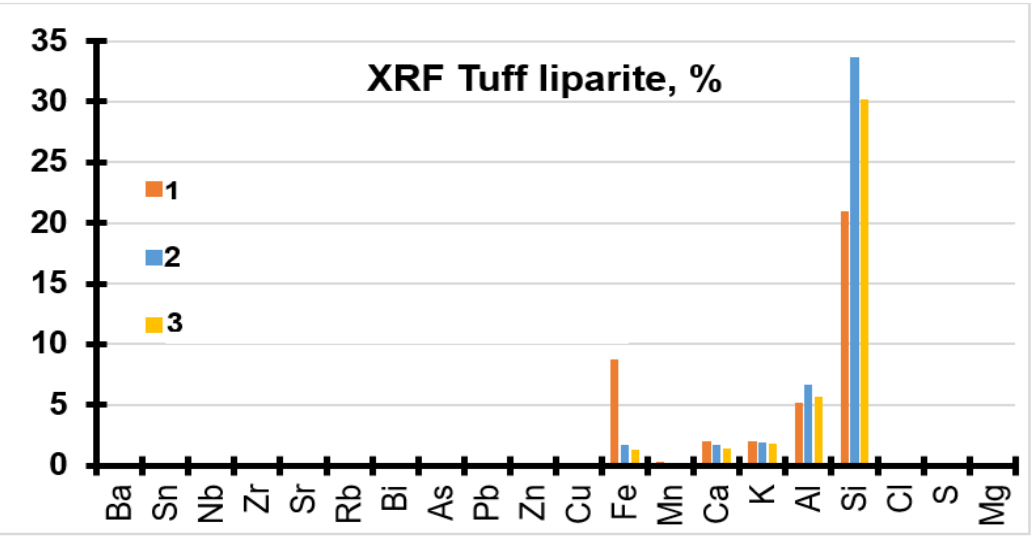

Fig. 5. Results of XRF analysis of liparite tuff samples depending on the occurrence horizon: 1 $1480 ; 2-1500$ and $3-1516$.

Table 2 shows the content of elements, including those that are not displayed in graph 5 in the form of information columns.

The obtained experimental data on the XRF study of tuff samples do not contradict the geological characteristics of the deposit.

Table 2. The results of XRF analysis for samples of liparite tuff 1-3 expressed in \%.

\begin{tabular}{|c|c|c|c|c|c|c|c|c|c|c|}
\hline $\begin{array}{c}\text { Reading } \\
\text { No }\end{array}$ & $\mathbf{B a}$ & $\mathbf{S n}$ & $\mathbf{N b}$ & $\mathbf{Z r}$ & $\mathbf{S r}$ & $\mathbf{R b}$ & $\mathbf{B i}$ & $\mathbf{A s}$ & $\mathbf{P b}$ & $\mathbf{Z n}$ \\
\hline 1 & 0.0408 & 0.0237 & 0.0138 & 0.0187 & 0.0051 & 0.0421 & 0.0014 & 0.0192 & 0.0003 & 0.0301 \\
\hline 2 & 0.0185 & 0.0004 & 0.0186 & 0.0182 & 0.0106 & 0.0109 & 0.0018 & 0,0018 & 0.002 & 0.0057 \\
\hline 3 & 0.0556 & 0 & 0.0096 & 0.0125 & 0.0109 & 0.0167 & 0.0086 & 0 & 0.0032 & 0.0079 \\
\hline $\begin{array}{c}\text { Reading } \\
\text { No }\end{array}$ & $\mathbf{C u}$ & $\mathbf{F e}$ & $\mathbf{M n}$ & $\mathbf{C a}$ & $\mathbf{K}$ & $\mathbf{A l}$ & $\mathbf{S i}$ & $\mathbf{C l}$ & $\mathbf{S}$ & $\mathbf{M g}$ \\
\hline 1 & 0.0617 & 8.7622 & 0.3276 & 2.033 & 2.0354 & 5.2108 & 20.927 & 0.0387 & 0,0944 & 0.2071 \\
\hline 2 & 0.0046 & 1.7017 & 0.029 & 1.6942 & 1.9443 & 6.6806 & 33.658 & 0.0512 & 0.194 & 0.0638 \\
\hline 3 & 0.0081 & 1.2858 & 0.0383 & 1.4026 & 1.823 & 5.6453 & 30.204 & 0.0428 & 0.025 & 0 \\
\hline
\end{tabular}

Note: $A$ value of " 0 " indicates an element content of at least 1 ppm.

The final results of the XRD for the determination of elements in samples of liparite tuff and quartz metasomatites with arsenopyrite and tourmaline of the studied groups of samples are shown in Figure 6.

Samples 3, 6 and 1 are respectively samples of liparite tuff numbered 1, 2 and 3 shown in Figure 5. From samples 1-6, sample No. 5 was similar in look to the sample with a high content of sulfides. However, the XRF analysis performed by the NITON XL2 spectrometer showed the presence of the maximum Si content, the minimum $\mathrm{S}$ and As content in this sample, and also the presence of a wide range of metals (from $\mathrm{Sb}$ to $\mathrm{Fe}$ and $\mathrm{Mn}$ ) whose oxides and/or complex compounds give the quartz component a distinct yellow hue. The mineral components of the rocks samples 1, 3-5 horizon 1500 and 2, 6 horizon 1516 in their composition have a content of chemically bound sulfur (in the composition of arsenopyrite FeAsS) less than $1 \%$. The content of As varies very widely from $0 \%$ to $12 \%$ and its compounds, the main of which are arsenopyrite (FeAsS) and lellingite (FeAs2) are present both at horizon 1500 and horizon 1516. The large amount of $\mathrm{Al}$ and $\mathrm{Si}$ is explained 
by the fact that the host rock consists of quartzites and aluminosilicates, and also other components of the ore mass, for example, tourmaline contained in the form of inclusions can have the following gross formula $\mathrm{Na}(\mathrm{Li}, \mathrm{Al}) 3 \mathrm{Al} 6[(\mathrm{OH}) 4 \mathrm{I}(\mathrm{BO} 3) \mathrm{Si} 6 \mathrm{O} 18]$.

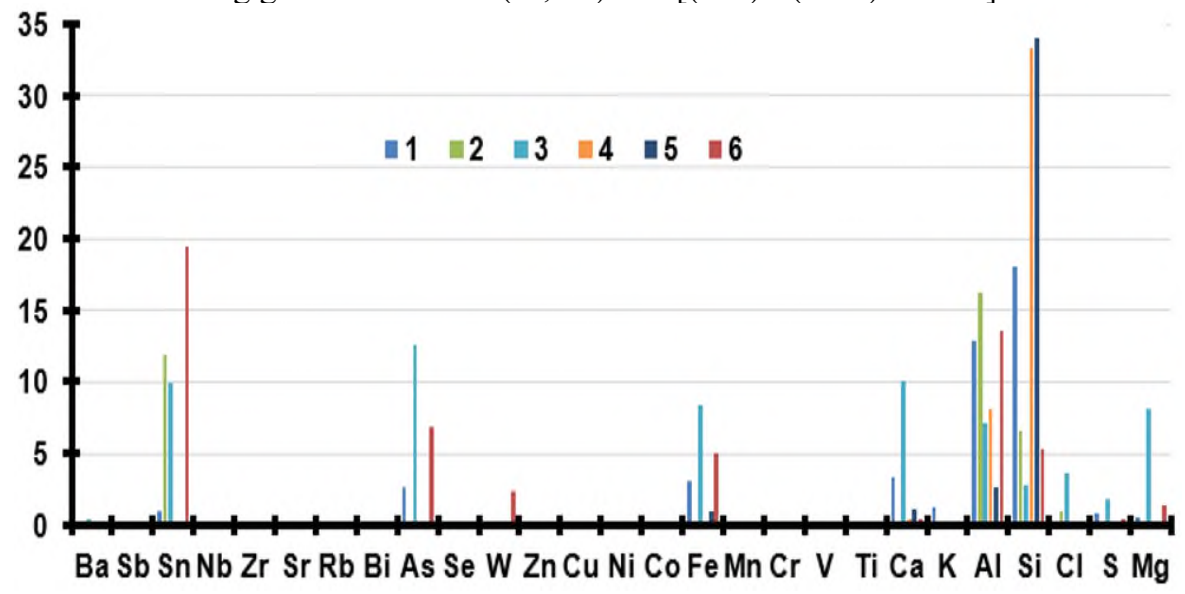

Fig. 6. Results of the XRF study of a representative sample of each samples 1-6.

\section{Conclusion}

Due to the fact that the XRF method is not recognized in any country as a method for determining the explosion and fire hazard of the studied substances, we still consider its use appropriate in the case of complete absence of sulfur in one form or another in the samples of the host rock or with a content of less than $10 \%$. In addition, based on the obtained data, we believe that the method of X-ray fluorescence analysis can be used as an express method for assessing the risk of spontaneous combustion and explosions of rock sulfurcontaining dust and is taken as the basis for operational monitoring of industrial safety in underground operations related to the mining of ore bodies containing pyrite sulfur considered in this article.

\section{References}

1. N.A. Teterev, A.I. Ermolaev, A.M. Kuznetsov, Mining Inf. Anal. Bull. 12(SI63), 3-11 (2018) DOI:10.25018/0236-1493-2018-12-63-3-11

2. M.R. Dmitrievich, R.V. Alekseevich, S.V. Borisovich, International Journal of Civil Engineering and Technology 10(2), 1154-1161 (2019) Article ID: IJCIET_10_02_112

3. E.I. Kabanov, G.I. Korshunov, V.A. Rodionov, Gornyi Zhurnal 8, 85-88 (2019) DOI: 10.17580/gzh.2019.08.17

4. S.Ya. Zhikharev, V.A. Rodionov, L.V. Pikhkonen, Gornyi Zhurnal 6, 45-49 (2018) DOI: 10.17580/gzh.2018.06.09

5. Z.A. Abiev, V.A. Rodionov, G.P. Paramonov, V.I. Chernobay, Mining Inf. Anal. Bull. 5, 26-34 (2018) DOI: 10. 25018/0236-1493-2018-5-0-26-34

6. N.A. Teterev, A.I. Ermolaev, A.M. Kuznetsov, Mining Inf. Anal. Bull. 12(SI63),12-19 (2018) DOI: 10.25018/0236-1493-2018-12-63-12-19

7. R.R. Vagapov, V.A. Rodionov, Oil Industry 11, 123-125, (2010) 
8. M.V. Rylnikova, N.A. Mitishova, Mining Inf. Anal. Bull. 9, 41-51 (2019) DOI:10.25018/0236-1493-2019-09-0-41-51

9. Q. Zhang, Q. Ma, B. Zhang, Journal of Loss Prevention in the Process Industries 29 (1), 8-12 (2014)

10. P. Amyotte, Process Safety and Environmental Protection 92(4), 292-299 (2014)

11. Zh. Yuan, N. Khakzad, F. Khan, P. Amyotte, Process Safety and Environmental Protection 98, 57-71 (2015)

12. F. Yang, C. Wu, Z. Li, Journal of Loss Prevention in the Process Industries 2, 131-137 (2011)

13. F. Yang, C. Wu, Transactions of Nonferrous Metals Society of China 1, 276-282 (2013)

14. V.A. Rodionov, V.D. Tsygankov, S.Ya. Zhikharev, Proceedings of the Tula States University-sciences of Earth 1, 145-158 (2020) DOI: 10.46689/2218-5194-2020-1-1145-158

15. G.I. Aynbinder, M.D. Demchishin, E.A. Gubina, V.V. Vdovina, S.A. Zuev, M.O. Devlikanov, Fire safety 4, 70-73 (2017)

16. S.A. Kozyrev, E.A. Vlasova, Herald of the Kola Science Centre of RAS 2(11), 54-60 (2019) DOI: 10.25702/KSC.2307-5228.2019.11.2.54-60

17. A.B. Bakirov, T.K. Valeev, R.A. Suleimanov, N.R. Rakhmatullin, Z.B. Baktybaeva, Hygiene and Sanitation, Russian journal 98(9), 917-922 (2019) DOI: http://dx.doi.org/ 10.18821/0016-9900-2019-98-9-917-922

18. A.G.Krivitsky, V.A. Rodionov, S.Ya Zhiharev., L.V.Pikhkonen, Proceedings of the Tula States University-sciences of Earth 2, 154-162 (2018)

19. N.A. Chumakov, M.V. Tumanov, A.A. Zakharov, Proceedings of 2018 17th Russian Scientific and Practical Conference on Planning and Teaching Engineering Staff for the Industrial and Economic Complex of the Region 156-158 (2018) DOI: https://doi.org/10.1109/ptes.2018.8604189

20. V.A. Rodionov, V.A. Tursenev, I.L. Skripnik, Yu.G. Ksenofontov, Journal of Mining Institute 246, 617-622 (2020) DOI: 10.31897/PMI.2020.6.3 